\title{
Etiology and Immediate Outcome of Neonatal Convulsions: A Hospital Based Study
}

Salina Haque ${ }^{1}$

Shahadat Hossain ${ }^{2}$

Mitra Datta ${ }^{1}$

Mohammed Maruf-Ul-Quader ${ }^{3}$

'Department of Pediatrics

Chattogram Medical College

Chattogram, Bangladesh.

${ }^{2}$ Department of Pediatrics

Institute of Applied Health Sciences (IAHS)

Chattogram, Bangladesh.

${ }^{3}$ Department of Pediatrics Nephrology * Chattogram Medical College

Chattogram, Bangladesh.

*Correspondence to:

\section{Dr. Salina Haque}

Assistant Professor

Department of Pediatrics

Chattogram Medical College

Chattogram, Bangladesh.

Mobile : +8801714087845

Email: bappita@yahoo.com

Date of Submission : 10.09 .2019

Date of Acceptance : $\quad 09.10 .2019$

www.banglajol.info/index.php/CMOSHMC

\begin{abstract}
Background: Neonatal seizures are the most common manifestation of neurological disorders in the newborn period and an important determinant of outcome To evaluate the causes and immediate outcome in hospital of neonatal convulsions.
\end{abstract}

Materials and methods: This hospital based prospective study was conducted in Special Care Neonatal Unit (SCANU) Department of Paediatrics and Child Health Bangabandhu Memorial Hospital (BBMH) USTC, including 30 neonates suffering from convulsion from 1 to 28 days of age during the period of 1st July to 30th October, 2003.

Results: Twenty-four (80\%) cases were under 5 days age, 4 (13.33\%) cases were ranged 6 to 15 days age. The mean age of the patients was 3 days. 18 (60\%) babies were male and 12 (40\%) were female. Male:female ratio was 1.5:1. Twenty (66.67\%) babies had normal body weight (2500-4000 g). Maternal complications during pregnancy were present in 10 (33.33\%) cases. Convulsion was present in all 30 (100\%) cases. Depressed primitive reflexes were found 16 (53.33\%) cases, cyanosis in $5(16.67 \%)$ cases, fever in 7 (23.33\%) cases. Subtle seizures were present in 16 (53.33\%) cases, focal clonic and focal tonic seizures were present in $7(23.33 \%)$ and $4(13.33 \%)$ cases, respectively. Generalized tonic seizures were present in $3(10 \%)$ cases and none (0\%) cases had myoclonic seizure. Onset of convulsion in relation to age revealed that 13 (43.33\%) cases had convulsion before 24 hours of age, 10 (33.33\%) developed convulsion between 1-3 days of age, 5 (16.67\%) and 2 (6.67\%) had convulsion between 4-7 days and 8-21 days of age respectively. Commonest cause of neonatal convulsion was found to be Hypoxic-Ischaemic Encephalopathy (HIE). It was found in 17 (56.67\%) patients. Hypoglycaemia as primary metabolic cause was found in 4 (13.33\%) patients, and septicaemia was found in 3 (10\%) patients. Eighteen (60\%) cases stayed in hospital for 7-10 days, out of which 16 (53.33\%) were cured and 2 (6.67\%) died. Three (10\%) cases stayed in hospital for 4-5 days, all of them were cured, Two (6.67\%) cases stayed in hospital for 3 days and among them 1 (3.33\%) died and another was cured and discharged on request. Five cases (16.67\%) stayed for 11-14 days in hospital, out of them 3 (10\%) were cured and 2 (6.67\%) expired. Only 1 case (3.33\%) stayed for more than 14 days and died at day 20. The mortality rate in this study is $20 \%$.

Conclusion: The most common cause of neonatal seizure was HIE (56.67\%). Other causes of neonatal convulsions are septicaemia, meningitis, primary metabolic disorders like hypoglycaemia and hypocalcaemia, intraventricular haemorrhage and some causes are still unknown. Mortality due to neonatal convulsion is still very high, and in this series, it was found to be 20 percent. Survival while staying in hospital occurred in 24 (80\%) cases.

Key words: Neonatal Convulsions; Etiology; Outcome. 


\section{INTRODUCTION}

A seizure is a sudden, transient disturbance of brain function, manifested by involuntary motor, sensory, automatic or psychic phenomena, alone or in any combination, often accompanied by alteration or loss of consciousness ${ }^{1}$.

A seizure is defined clinically as a paroxysmal alteration of neurological function, i.e. behavioural, motor and/or autonomic function. This definition encompasses both clinical phenomena that correlate temporally with seizure activity recorded by surface electrodes and are, therefore, clearly epileptic, i.e related to hypersynchronous electrical discharges, as well as stereotypic, paroxysmal clinical phenomena which are not associated clearly with electrographic seizures ${ }^{2}$. Thus, approximately 65 percent of neonatal seizures are not clearly associated with apparent cortical Electrographic seizure activity on the basis of electroencephalography (EEG) records from surface electrodes ${ }^{3,4}$.

Neonatal seizures represent a major manifestation of significant neurological disease in the newborn, e.g. hypoxic-ischaemic cerebral injury, meningitis, trauma, cerebral dysgenesis ${ }^{5}$. Seizures may be the most frequent clinical sign of Central Nervous System (CNS) dysfunction in the newborn, their presence requires a thorough investigation for potentially treatable causes of the underlying CNS disorder ${ }^{6}$.

Neonates are at particular risk for the development of seizures because metabolic, toxic, structural and infectious diseases are more likely to be manifested during this time than at any other period of life ${ }^{7}$. Seizures are the most distinctive manifestation of neurologic dysfunction in the newborn infant. Moreover, neonatal seizures often herald potentially devastating forms of brain injury ${ }^{8}$. Convulsions are more frequent on the first day of life than at any other time, although the diagnosis is easily missed because their manifestations can be extremely subtle ${ }^{9}$.

Neonatal seizures may be difficult to recognize clinically and some neonatal behaviours that were considered previously to be convulsions are not substantiated by the EEG recording ${ }^{7}$. The clinical manifestations of seizures in the newborn differ from those of older infants or children primarily because of the rapid rate of brain development near term and the types and number of aetiological factors that may be responsible for brain injury during the neonatal period ${ }^{6}$. Nonetheless, several clinical features distinguish seizures from nonepileptic activity in neonates. Autonomic changes, such as tachycardia and duration of blood pressure, are common with seizures but do not occur with nonepileptic events ${ }^{6}$. Jitteriness resembling simple tremors may be stopped by holding the infant's extremity; it often depends on sensory stimulus and occurs when infant is active and it is not associated with abnormal eye movements ${ }^{10}$. Techniques such as bedside video-electroencephalogram monitoring and magnetic resonance imaging (MRI) have challenged earlier beliefs and raised fundamental questions regarding the diagnosis, aetiology and management of seizures in the newborn infants.
Early diagnosis, prompt investigation for underlying aetiology is an urgent, vigorous treatment with anticonvulsants are of critical importance because delayed recognition of treatable causes, e.g. hypoglycaemia, may have a profound effect on outcome. Secondly, prolonged seizures may interfere significantly with cardiorespiratory stability. Finally, there are experimental data which suggest that prolonged seizures per se may contribute to the severity of injury in the immature brain ${ }^{10}$. Seizures may adversely affect the subsequent neurodevelopmental outcome and even predispose to nonneonatal seizures ${ }^{10}$. Neonatal seizures type differ considerably from seizures observed commonly in older children, principally because the newborn infant is less to sustain organized, generalized epileptiform discharges ${ }^{11}$. Mortality rate ranges between 15 and 18 percent in clinically diagnosed cases and as high as 32 percent $^{14}$. The two most useful parameters for prediction of outcome are the underlying aetiology of the seizures and the characteristics of the EEG. Again, there appears to be a much higher incidence of sequelae $(55 \%)$ following EEG-confirmed neonatal seizures ${ }^{5,12-14}$. The prognosis of neonatal seizure has improved considerably during the past two decades mainly in terms of mortality rate. Regardless of their precise incidence, it is clear that seizures are more common in the newborn period than at any other time in life, and that the tendency toward recurrent seizures and status epilepticus is far greater in the newborns ${ }^{8}$.

\section{MATERIALS AND METHODS}

This hospital based prospective study was conducted in Special Care Neonatal Unit (SCANU) Department of Paediatrics and Child Health, Bangabandhu Memorial Hospital (BBMH) USTC, including 30 neonates suffering from convulsion from 1 to 28 days of age during the period of 1st July to 30th October, 2003. All the cases were within first 28 days of their life. Male and female newborns were selected consecutively. Newborns who had lethal congenital anomalies, e.g cerebral agenesis, anencephaly, spina bifida and newborns with birth weight less than $750 \mathrm{~g}$ were excluded from the study. The neonatal unit is well staffed and equipped to manage critically ill neonates. It is situated in the centre of the commercial capital, Chattogram and it is a referral centre for neonatal intensive care. Sick babies are referred from hospitals, maternity, clinics and mostly coming from urban areas. For each neonate, detailed history was taken and physical examination was done as per set questionnaire. Informant was in most cases mothers of the neonates. Obstetrical history was taken from mothers and from birth records A Gestational age of the newborns was determined by the date of the mother's last menstrual period and was confirmed by Expanded New Ballard Scoring (NBS) system, which is accurate \pm 2 weeks.

As the duration of this hospital-based study was only for four months, only immediate outcome in hospital was assessed, which was categorized as follows: i) Survived: This group included the babies who had no convulsion for minimum period 
of 3 days, showing good primitive reflexes and activity, maintaining normal body temperature in room air, feeding well and gaining weight. ii) Expired: Mortalities during hospital stay. All the relevant information (History, findings on physical examination, etc. were recorded on a predesigned questionnaire and data were compiled at the end of the study.

\section{RESULTS}

Table I shows that out of 30 patients, $24(80 \%)$ were aged between 0-5 days, 4 (13.33\%) were between 6-15 days. The study shows that neonatal convulsion is more common in first week of life than later on. The mean age was 3 days. The study shows male predominance. Male-female ratio was 1.5:1. Maximum $20(66.67 \%)$ cases were of body weight between 2500-4000g. Majority 24 (80 \%) were of $37-42$ weeks gestational age. $25(83.33 \%)$ were delivered by normal vaginal delivery. Rest 5 (16.67\%) were delivered by Caesarean section.

Table I : Demographic characteristics of the study subjects $(n=30)$

\begin{tabular}{|c|c|c|}
\hline Demographic characteristics & Number of patients & Percentage (\%) \\
\hline \multicolumn{3}{|l|}{ Age (days) } \\
\hline $0-5$ & 24 & 80.00 \\
\hline $6-15$ & 4 & 13.33 \\
\hline $16-28$ & 2 & 6.67 \\
\hline \multicolumn{3}{|l|}{ Sex } \\
\hline Male & 18 & 60.00 \\
\hline Female & 12 & 40.00 \\
\hline \multicolumn{3}{|l|}{ Weight } \\
\hline$<2000$ & 2 & 6.67 \\
\hline $2000-2499$ & 8 & 26.67 \\
\hline $2500-4000$ & 20 & 66.67 \\
\hline \multicolumn{3}{|l|}{ Gestational age (weeks) } \\
\hline $32-6$ & 5 & 16.67 \\
\hline $37-42$ & 24 & 80.00 \\
\hline$>42$ & 1 & 3.33 \\
\hline \multicolumn{3}{|l|}{ Mode of delivery } \\
\hline Normal vaginal delivery & 25 & 83.33 \\
\hline Caesarean section & 5 & 16.67 \\
\hline \multicolumn{3}{|l|}{ Maternal complication } \\
\hline Preeclamptic toxaemia & 2 & 6.67 \\
\hline Eclampsia & 1 & 3.33 \\
\hline Primary hypertension & 1 & 3.33 \\
\hline Antepartum haemorrhage & 1 & 3.33 \\
\hline Diabetes mellitus & 2 & 6.67 \\
\hline Prolonged labour & 2 & 6.67 \\
\hline Early rupture of membrane & 1 & 3.33 \\
\hline
\end{tabular}

Table II shows that subtle seizure, i.e. random movements of eye, blinking, repeated chewing movement, rotatory limb movements, e.g. swimming, pedaling and autonomic disturbance like apnoea were found in 16 (53.33\%) patients. Focal clonic and focal tonic seizures were present in 7 $(23.33 \%)$ and $4(13.33 \%)$ patients, respectively. Generalized tonic type was found in $3(10 \%)$ patients. None of the patients showed myoclonic type of seizure.
Table II : Nature of convulsion of studied cases $(n=30)$

\begin{tabular}{llcc} 
Type & Clinical feature & $\begin{array}{c}\text { Number of } \\
\text { patients }\end{array}$ & Percentage \\
Subtle & $\begin{array}{l}\text { Random and roving eye, } \\
\text { movements, chewing, } \\
\text { sucking, swimming, } \\
\text { pedaling movements of }\end{array}$ & & \\
& limbs & & \\
Focal clonic & $\begin{array}{l}\text { Repetitive rhythmic } \\
\text { contractions of muscle } \\
\text { groups of limbs, face, trunk }\end{array}$ & 73.33 & \\
Focal tonic & $\begin{array}{l}\text { Sustained posturing of single } \\
\text { upper/lower limb }\end{array}$ & & \\
Generalized tonic & $\begin{array}{l}\text { Sustained symmetric } \\
\text { posturing of limbs, Trunk }\end{array}$ & 3 & 13.33 \\
Myoclonic & $\begin{array}{l}\text { Arrhythmic contractions of } \\
\text { muscle groups of } \\
\text { limbs, face or trunk }\end{array}$ & & 10.00 \\
\hline
\end{tabular}

Table III shows that $13(43.33 \%)$ patients were below 1 day age when convulsion started, $10(33.33 \%)$ patients were between 13 days old, 5 (16.67\%) patients were 4-7 days old, and only 2 $(6.67 \%)$ patients were of more than 7 days old.

Table III : Onset of convulsion in relation to age $(\mathrm{n}=30)$

\begin{tabular}{lcc} 
Age (days) & Number of patients & Percentage \\
$<1$ & 13 & 43.33 \\
$1-3$ & 10 & 33.33 \\
$4-7$ & 5 & 16.67 \\
$8-21$ & 2 & 6.67 \\
\hline
\end{tabular}

CSF study was none in 5 patients. Out of them, 3 were found normal study, but pressure was increased in 2 patients. In one patient, the physical appearance was turbid, TC was 2000 cells per cumm, glucose $40 \mathrm{mg} / \mathrm{dl}$, protein $300 \mathrm{mg} / \mathrm{dl}$, cells were predominantly neutrophil and culture showed no growth. In the other one, CSF was clear, TC was 300 cells/cumm, glucose 45 $\mathrm{mg} / \mathrm{dl}$, protein $80 \mathrm{mg} / \mathrm{dl}$, cells were predominantly lymphocyte, and this CSF also showed no growth on culture.

- Blood cultures were done in 3 patients; one showed no growth. Of the other 2, 1 (3.33\%) showed growth of E. coli and other showed growth of Klebsiella in culture specimen. CRP was done in 5 (16.67\%) patients. All patients had raised CRP (> $10 \mathrm{mg} / \mathrm{dl})$.

- I/T ratio was done in 3 patients. One $(3.33 \%)$ had ratio 0.4 and other $2(6.67 \%)$ had ratio 0.5 .

- EEG was not done in any patient due to their financial background or sometimes due to not necessary.

- TORCH antibody titre done in 2 patients revealed no antibody. 
- Serum bilirubin level was done in 2 patients with jaundice. Both showed unconjugated hyperbilirubinaemia. Total bilirubin level was $<12 \mathrm{mg} / \mathrm{di}$ in both cases.

- Cranial USG was done in 5 patients. Only one revealed intraventricular haemorrhage, and he was a premature LBW $(1.4 \mathrm{~kg})$ baby.

- VDRL and serum HBsAg was done in 2 patients and both showed no abnormality.

- Blood urea and serum creatinine was done in 3 asphyxiated patients. One was in the normal range and other 2 had raised serum creatinine and blood urea.

- Hct was done in 2 patients. One had Hct 54\% and the other one $40 \%$.

Table IV : CSF study of patients of meningitis $(\mathrm{n}=2)$

\begin{tabular}{lcc} 
CSF study & Case No. 1 & Case No. 2 \\
Pressure & Increased & Increased \\
Physical appearance & Turbid & Clear \\
Total count (per cumm) & 2,000 & 300 \\
Glucose level (mg/dl) & 40 & 45 \\
Protein level (mg/di) & 60 & 55 \\
Predominant cell type & Neutrophil & Lymphocyte \\
Growth on culture & No growth & No growth \\
\hline
\end{tabular}

Table V shows that hypoxic ischaemic encephalopathy (HIE) was the commonest cause of neonatal convulsion in this study. HIE was found in 17 (56.67\%) patients. Infection in the form of septicaemia and meningitis were found in $3(10 \%)$ and 2 (6.67\%) patients, respectively. Next common cause was hypoglycaemia $4(13.33 \%)$. Two patients $(6.67 \%)$ had hypocalcaemia. One $(3.33 \%)$ patient had intraventricular haemorrhage. No cause was found in $1(3.33 \%)$ patient.

Table V : Outcome of convulsion in studied cases $(n=30)$

$\begin{array}{lcc}\text { Aetiology } & \text { Number of patients } & \text { Percentage } \\ \begin{array}{l}\text { Hypoxic-ischemic } \\ \text { encephalopathy (HIE) }\end{array} & 17 & 56.67 \\ \text { Infections } & 3 & 10.00 \\ \quad \text { Septicaemia } & 2 & 6.67 \\ \quad \text { Meningitis } & & \\ \text { Intracranial haemorrhage } & 1 & 3.33 \\ \quad \text { Intraventricular } & 0 & 0.00 \\ \quad \text { Subarachnoid } & & \\ \text { Primary metabolic cause } & 4 & 13.33 \\ \quad \text { Hypoglycaemia } & 2 & 6.67 \\ \text { Hypocalcaemia } & 0 & 0.00 \\ \text { Congenital malformations of CNS } & 1 & 3.33 \\ \text { Unknown } & \end{array}$

Table VI shows that 2 patients $(6.67 \%)$ stayed in hospital for 3 days, 1 died at day 3, 1 left hospital by giving discharge on risk bond (DORB) due to their personal interest on day 3 . Three (10\%) patients stayed for 4-5 days and all survived and discharged.
Eighteen (60\%) patients had 7-10 days of hospital stay and out of them 16 were survived and 2 expired. Five (16.67\%) patients stayed for 11-14 days and 2 of them expired on day 12 and day 14 , respectively. Two $(6.67 \%)$ patients stayed for more than 14 days, 1 expired on day 20 and other one survived and discharged on day 18 . The overall mortality rate was 20 percent.

Table VI : Hospital outcome of studied cases $(n=30)$

\begin{tabular}{lcccc} 
Number of patients & Hospital stay (days) & Survived & Expired & Mortality (\%) \\
2 & 3 & 1 & 1 & 3.33 \\
3 & $4-5$ & 3 & 0 & 0.00 \\
18 & $7-10$ & 16 & 2 & 6.67 \\
5 & $11-14$ & 3 & 2 & 6.67 \\
2 & $>14$ & 1 & 1 & 3.33 \\
Total & & 24 & 6 & 20.00 \\
\hline
\end{tabular}

\section{DISCUSSION}

Seizures are the most distinctive manifestation of neurologic dysfunction in the newborn infant. Convulsion is an acute emergency during neonatal period and is responsible for significant number of mortality and morbidity during this period. Convulsions during the neonatal period should not be neglected and through examinations and investigations to find out the cause of seizure and urgent treatment to control convulsion is necessary.

In our study, mean age of the patients were 3 days. Twenty-four $(80 \%)$ cases were between $0-5$ days old. 18 (60\%) were male and $12(40 \%)$ were female. In Sarkar's study 54 percent was male ${ }^{15}$. In a study done in the United Kingdom by Minchom et al male babies were 55 percent ${ }^{16}$. Our study was consistent with these two studies in relation to sex as both of these studies revealed male preponderance. The cause of male prevalence in our study and Sarkar's study was most probably due to more preference to male than female ones in our country which is contributed to male dominant society ${ }^{15}$. Male-female ratio in our study was 1.5:1.

Mean weight of our studied cases was 2650g. 20 babies (66.67\%) ranged 2500-4000g. Among the 10 LBW babies $(33.33 \%), 5(16.67 \%)$ were premature, out of them $2(10 \%)$ were born at 33 weeks, $2(6.67 \%)$ were born at 35 weeks of pregnancy and $1(3.33 \%)$ at 28 weeks of pregnancy. Twentyfour patients $(80 \%)$ were born at $37-42$ weeks. In Sarkar's study, 70 percent babies had normal birth weight, which was nearly consistent with our study ${ }^{15}$.

Five (16.67\%) patients were delivered at hospital by Caesarean section and rest $25(83.33 \%)$ were born by normal vaginal delivery. Ten mothers (33.33\%) developed complications, eg preeclampsia, eclampsia, diabetes mellitus, prolonged labour and in the rest $20(66.67 \%)$, pregnancies were uneventful.

Subtle seizure was found in $16(53.33 \%)$ cases in our study. In a study by Mannan et al. ${ }^{17}$ subtle type of convulsion occurred in $27(54 \%)$ cases. Subtle seizures were the most common seizure type in several surveys, occurring in 75 percent of the cases described by Scher et $\mathrm{a}^{18}$. Focal tonic seizures were present in $7(23.33 \%)$ and $4(13.33 \%)$ patients, respectively. 
In this study, $3(10 \%)$ babies had convulsions lasting for more than 30 minutes. Most cases [15 (50\%)] had convulsion for less than 1 minute. Twelve (40\%) had convulsions persisting for 1-5 minutes. Duration of convulsion has prognostic value and seizures lasting for more than 30 minutes have poor outcome, especially if they are refractory to multiple anticonvulsant medications". In this series, the three cases (10\%) in whom each convulsion lasted for more than 30 minutes, died ultimately despite multiple anticonvulsant therapy, such as phenobarbitone, phenytoin, clonazepam, in combination, and also antibiotics. So, a good relationship between the duration and characteristic of seizure and bad outcome were found in this study. One $(3.33 \%)$ of them was a case of severe birth asphyxia with grade III HIE, other 2 cases were patients of septicaemia $(3.33 \%)$ and of unknown aetiology (3.33\%), respectively. According to Volpe, seizures most commonly begin prior to 24 hours of age of a baby, and approximately 50 percent occur within 12 hours5. In our present study, we also observed that $13(43.33 \%)$ patients developed seizure within 24 hours of their birth, which also supports the study of Volpe.

Of five patients having infection, total count of WBC were above $20,000 /$ cumm in $1(20 \%)$ patients, $2(40 \%)$ patients had total count $4,300 /$ cumm and 3,000/cumm, respectively. Two patients $(40 \%)$ had total count in between 15,000$20,000 /$ cumm. Neutrophil counts in all 3 patients with septicaemia were below 1000/cumm of blood.

In our study, 3 cases (10\%) had serum $\mathrm{Na}+$ level below 130 $\mathrm{mmol} / \mathrm{L}$, but none had below $120 \mathrm{mmol} / \mathrm{L}$. All 3 cases suffered from severe birth asphyxia and HIE. Our study was consistent with Sarkar's study who found no case under $120 \mathrm{mmol} / \mathrm{L}^{15}$. But Mannan et al. found $10(20 \%)$ cases of hyponatraemia in their study, incidence of hyponatraemia was highest in HIE ( $50 \%$ of HIE cases with biochemical changes) ${ }^{17}$. Kumar et al. found hyponatraemia in 37 percent cases of neonatal seizure due to perinatal asphyxia ${ }^{19}$. Findings of the present study was consistent with other studies in some aspects and different in other aspects.

Early onset hypocalcaemia occurs within first 3-4 days of life. Sarkar in his study found 1 (2\%) case of hypocalcaemia and it was early onset ${ }^{15}$. In our study, the two hypocalcaemic patients were treated with I/V 10\% Ca-gluconate and they responded well, their seizures stopped. Hypomagnesaemia usually occurs with hypocalcaemia in 50 percent cases73. Mannan et al. found $4(8 \%)$ babies in their study suffering from hypomagnesaemia ${ }^{17}$. But in this study, we found no case of hypomagnesaemia.

Meningitis was the cause in $2(6.67 \%)$ cases. They were confirmed by CSF study and their CRP levels were also high. In this study of 30 neonates in hospital, hypoxic-ischaemic encephalopathy was the commonest $(56.67 \%)$ cause of neonatal convulsion. Mannan et al. also found HIE as the commonest cause $(48 \%)$ of neonatal seizure in their study ${ }^{17}$. Our study is also consistent with some other studies done before, e.g. Kumar et al. ${ }^{19}$ and Brown et $\mathrm{al}^{20}$, who found HIE as the commonest cause of neonatal convulsion in their studies. Mizrahi also had similar observation and found HIE in 46 percent cases (highest) in his study ${ }^{3}$. Sarkar in his study done in 1995 also found the HIE to be the commonest (54\%) cause of neonatal convulsion ${ }^{15}$. All $3(10 \%)$ cases of septicaemia had CRP level $>10 \mathrm{mg} / \mathrm{dl}$ and their $\mathrm{I} / \mathrm{T}$ ratios were $>0.2$. Meningitis was the cause in 2 $(6.67 \%)$ cases. Out of them, 1 did not respond to treatment and died on day 12 of hospital stay. Among the septicaemic case, two were premature and LBW babies. Preterm infants have a 310 fold higher incidence of infection than fullterm, normal birth-weight infants do ${ }^{21}$.

Primary metabolic disorder was the third highest cause in this series. Out of $6(20 \%)$ cases, $4(6.67 \%)$ cases were hypoglycaemic and $2(6.66 \%)$ cases were hypocalcaemic. They were discussed here earlier.

In only $1(3.33 \%)$ case, intraventricular haemorrhage was found in this study, and it was diagnosed by USG of brain. The baby was born at 30 weeks of pregnancy and suffered from severe birth asphyxia with HIE grade III. In Sarkar's study, 2 cases of intraventricular haemorrhage and 1 case of subarachnoid haemorrhage were found ${ }^{15}$. Our study was consistent with these two studies. But the results may vary. Mizrahi found no case of intracranial haemorrhage in 1971, but 15 percent cases in 1986 as a cause of neonatal convulsion ${ }^{3}$. Mizrahi and Kellaway in 1998 found 16 percent cases with intracranial haemorrhage ${ }^{22}$. The incidence of intracranial haemorrhage varies from 2 to more than 30 percent in newborn depending on gestational age at birth and the type of intracranial haemorrhage ${ }^{5,9}$. In our study, the case of intraventricular haemorrhage was managed supportively and symptomatically, but the baby died at day 3 . In only $1(3.33 \%)$ case of present study, no definite cause was found. The patient was given all supportive treatment along with anticonvulsant. Pyridoxine injection was given while anticonvulsant failed to control seizure in this patient. But the patient did not respond and this baby died on day 7 by making fail all doctors efforts. Mannan et al. also could not find any cause of convulsion in 6 percent cases ${ }^{17}$. In 12 percent cases of Sarkar's study, no cause of convulsion was found ${ }^{15}$. The incidence of undetected case is as low as 2 percent (1986) and as high as 23 percent (1971) in Mizrahi's study ${ }^{3}$.

The overall prognosis for survival in neonatal seizures is around 85 percent, a significant improvement from earlier decades ${ }^{8}$. The recent mortality rate reported for neonatal seizures which were diagnosed by clinical criteria without EEG confirmation has ranged between 15 and 18 percent $^{5,13}$. In contrast, the mortality rate for seizures confirmed by EEG has been reported to be much higher, approximately 32 percent $^{14}$. In the present study, EEG was not done to, it is a very costly investigation and other times due to not much indicated. Mortality rate in this study was 24 percent and in Sarkar's study was 24 percent $^{15}$. Two cases out of 17 HIE (11.76\%) expired on day 10 and day 14 of hospital stay, respectively. One out of 3 septicaemia case $(33.33 \%)$ died on day 20 . The only case of intraventricular haemorrhage, died on day 3 and one case of unknown aetiology 
died on day 7 of hospital stay. In Sarkar study, aetiological distribution of death was-HIE $8(16 \%)$, IVH 2 (4\%), meningitis $1(2 \%)$, undiagnosed $1(2 \%)^{15}$. Premature babies with LBW and HIE have very poor outcome, and in our study also, of the 2 expired cases of HIE, both were of LBW and premature by birth. Intraventricular haemorrhage in premature and LBW babies also has usually poor outcome, and in the present study, this was proved.

Infants with flaccid coma with seizures gene: ally have unfavourable outcome, whereas with preserved consciousness, activity, reflexes and tone, have a better outcome ${ }^{13}$. In this series, treatment was given to flaccid babies in coma accordingly, but all of them ultimately expired over next few days of admission.

Finding of the present study was consistent with other studies in some aspects and different in other aspects. A study containing greater number of cases may overcome these differences, though varied associated factors like race, geography and socioeconomic conditions may have their individual effect on the problem. Further studies with large sample size will give us representative information regarding the aetiology and immediate outcome of neonatal seizures in our country.

\section{CONCLUSION}

It is very difficult to draw a definitive conclusion from such a small study, where samples were drawn from a tertiary level urban hospital. But it can be depicted from the study that hypoxic-ischaemic encephalopathy is the commonest cause of neonatal convulsion as since it was found in 17 (56.67\%) cases. Other causes of neonatal convulsions are septicaemia, meningitis, primary metabolic disorders like hypoglycaemia and hypocalcaemia, intraventricular haemorrhage and some causes are still unknown.

Mortality due to neonatal convulsion is still very high, and in this series, it was found to be 20 percent. Survival while staying in hospital occurred in $24(80 \%)$ cases.

\section{DISCLOSURE}

All the authors declared no competing interest. 


\section{REFERENCES}

1. Moe PG, Seay AR. Neurologic and muscular disorders. In: Hay WW Jr, Hayward AR, Levin MJ, Soudheimer JM, editors. Current pediatric diagnosis and treatment. 15th ed. New York: McGraw-Hill Companies. 2001;632-98.

2. Volpe JJ. Neonatal seizures: Current concepts and revised classification. Paediatrics. 1989; 84:422-428.

3. Mizrahi EM. Neonatal seizures: problems in diagnosis and classification. Epilepsia. 1987; 28:546-555.

4. Mirza EM, Kellway P. Characterization and classification of neonatal seizures. Neurology. 1987;37:1837-1844.

5. Volpe JJ. Neurology of the newborn. Philadelphia: WB Saunders Company. 1987:129-1.58

6. Goddard-Finegold J, Mizrahi EM, Lee RT. The newborn nervous system. In: Taeusch HW, Ballard RA, editors. Avery’s diseases of the newborn. 7th ed. Philadelphia: WB Saunders Company. 1998; 871-891.

7. Johnston MV. Neonatal seizures. In: Behrman RE, Kliegman RM, Jenson HB, editors. Nelson textbook of pediatrics. 17th ed. Philadelphia: WB Saunders Company. 2004;7-8.

8. Du Plessis AJ. Neonatal seizures. In: Cloherty JP, Eichenwald EC, Stark AR, editors. Manual of neonatal care. 5th ed. Philadelphia: Lippincott Williams and Wilkins Company.2004;507-523.

9. McIntosh N. Convulsions in the newborn. In: Campbell AGM, McIntosh N, editors. Forfar and Arneil's textbook of paediatrics. 5th ed. London: Churchill Livingstone Company.1998: 244-247.

10. Barbara JS, Robert MK. Clinical manifestations of diseases in newborn period. In: Behrman RE, Kliegman RM, Jenson HB, editors. Nelson textbook of pediatrics. 17th ed. Philadelphia: WB Saunders Company. 2004;559-560.

11. Hill A, Volpe JF. Neonatal seizures. In: Robertson NRC, editor. Textbook of neonatology. Part II, 2nd ed. London: Churchill Livingstone Company. 1992;1043-1055.

12. Lomborso CT. Pronogis in neonatal seizures. In: Advances in neurology: status elilepticus. Vol. 34. New York: Raven. 1983:100-113.

13. Bergman et al. Outcome in neonates with convulsions treated in ICU. Ann Neurol. 1983;14:642-647.

14. Clancy RR, Legido A. Neurologic outcome after EEG proven seizures. Paediat Res. 1987; 21:489A.

15. Sarkar SMWA. Neonatal convulsions-etiology and outcome [Dissertation]. Dhaka: Bangladesh College of Physicians and Surgeons. 1995.

16. Minchom et al. Antecedents and outcome of very early seizures in newborn at or after term. Br J Obstet Gynaecol. 1987;94:431-439.

17. Mannan MA, Islam MN, Rahman SA. Aetiology of neonatal seizure and biochemical changes associated with them: A hospital based study. Bangladesh Child Health. 2000;24:55-59.

18. Scher MS, Aso K, Beggarly ME. Electrographic seizures in preterm and fullterm neonates: Clinical correlates, associated brain lesions and risk for neurlogic sequelae. Pediatrics. 1993;7:363-368.

19. Kumar A, Gupta N, Kachhauaha JS, Singha PN. Biochemical abnormalities in neonatal seizures. Ind Pediatr. 1995; 32:424-428.

20. Brown JK, Cockburn F, Forfar JO. Clinical and chemical correlates in the convulsions of the newborns. Lancet. 1972; 1:135-139.

21. Barbara JS. Infections of neonatal infant. In: Behrman RE, Kliegman RM, Jenson HB, editors. Nelson textbook of pediatrics. 17th ed. Phildelphia: WB Saunders Company. 2004;623-640.

22. Mizrahi EM, Kellaway P. Diagnosis and management of neonatal seizures. New York: Lippincott Raven. 1998. 